\title{
High Temperature Steam Oxidation of SiC Coating Layer of TRISO Fuel Particles
}

\author{
Kurt A. Terrani ${ }^{1}$, Chinthaka M. Silva \\ Oak Ridge National Laboratory, Oak Ridge, TN 37831, USA
}

\begin{abstract}
High-temperature oxidation behavior of $\mathrm{SiC}$ coating layer of TRISO fuel particles in $1500-1700^{\circ} \mathrm{C}$ steam at $1 \mathrm{~atm}$ has been examined inside a zirconia furnace. The $\mathrm{SiC}$ coating layers experienced a thickness loss of less than $2.5 \mu \mathrm{m}$ under these conditions up to $24 \mathrm{~h}$. The thickness of the oxide layer formed under these conditions was consistent with prior steam oxidation tests on high-purity bulk $\mathrm{SiC}$. Upon reducing the presence volatile impurities from the test environment (particularly Al) by conducting the tests inside a zirconia furnace, melting of the silica layer at $1700^{\circ} \mathrm{C}$ was avoided.
\end{abstract}

\section{Introduction}

Since its original application as a coating layer in tristructural isotropic (TRISO) fuel particles of high temperature gas-cooled reactors (HTGRs) [1-2], $\mathrm{SiC}$ has been a topic of active research and development for nuclear energy applications [3]. Given today's focus on accident tolerant fuels for light water reactors (LWRs) [4], concepts utilizing $\mathrm{SiC}$ as core constituents [5-6] are receiving ample attention. This is the case since high-purity bulk $\mathrm{SiC}$ materials have been shown to exhibit exceptional resistance to oxidation in high-temperature steam environments [7-10]. In this study, high-temperature steam oxidation behavior of $\mathrm{SiC}$ coating layer of TRISO fuel particles has been examined. The majority of test conditions, consisting of $100 \% \mathrm{H}_{2} \mathrm{O}$ at elevated temperatures $\left(1500-1700^{\circ} \mathrm{C}\right)$, are unique and depart from what is considered applicable for HTGRs under normal and most accident conditions. Under normal operating conditions for HTGRs, only a small partial pressure of water vapor is expected to be present $(<1.4 \mathrm{~Pa}$ [11]) and under severe accidents the combination of high water vapor partial pressure ( $10^{5} \mathrm{~Pa}$ and higher) and elevated temperatures of this study are unlikely [12]. However, for the LWR application of TRISO fuel particles as microencapsulated fuel forms [13], namely fully ceramic microencapsulated (FCM) pellet, severe accidents beyond the design basis can lead to these high temperatures in presence of abundant steam.

FCM fuel consists of TRISO fuel particles embedded inside a sintered $\mathrm{SiC}$ matrix. The matrix $\mathrm{SiC}$ is consolidated at temperatures $<1900{ }^{\circ} \mathrm{C}$ using addition of a small amounts $(\sim 5 \mathrm{wt} \%)$ of sintering aides

\footnotetext{
${ }^{1}$ Corresponding author: terranika@ornl.gov, 865-576-0264
}

This manuscript has been authored by UT-Battelle, LLC under Contract No. DE-AC05-00OR22725 with the U.S. Department of Energy. The United States Government retains and the publisher, by accepting the article for publication, acknowledges that the United States Government retains a non-exclusive, paid-up, irrevocable, world-wide license to publish or reproduce the published form of this manuscript, or allow others to do so, for United States Government purposes. The Department of Energy will provide public access to these results of federally sponsored research in accordance with the DOE Public Access Plan (http://energy.gov/downloads/doe-public-access-plan). 
[14]. These sintering aides generally consist of a mixture of yttria-alumina $\left(\mathrm{Y}_{2} \mathrm{O}_{3}-\mathrm{Al}_{2} \mathrm{O}_{3}\right)$, where the latter compound is more prominent in the mixture. The focus of this study is on the oxidation behavior of the $\mathrm{SiC}$ coating layer of the TRISO fuel particle. Although some literature is available on oxidation behavior of sintered $\mathrm{SiC}$ [15-17], future studies will focus on determining the steam oxidation behavior of the FCM $\mathrm{SiC}$ matrix under similar conditions.

\section{Experimental Procedure}

For the purposes of oxidation tests, TRISO particles were intentionally produced without the outer pyrocarbon (PyC). The particle coating started with $\sim 520 \mu \mathrm{m}$ zirconia kernels coated with PyC $(\sim 40 \mu \mathrm{m})$. These particles were subsequently coated with CVD $\mathrm{SiC}$ at ORNL's $50 \mathrm{~mm}$ coater using methyl trichlorosilane (MTS), $\mathrm{CH}_{3} \mathrm{SiCl}_{3} . \mathrm{H}_{2}$ gas was mixed with the MTS as the fluidization medium (essentially carrier gas that was bubbled through MTS liquid). The coating conditions consisted of a $2 \mathrm{~h}$ run time at $1550^{\circ} \mathrm{C}$ with $\mathrm{H}_{2}$ and MTS flow at 14800 and $166 \mathrm{sccm}$. This resulted in formation of a dense SiC layer at the outermost surface with a thickness of $\sim 32 \mu \mathrm{m}$.

Oxidation testing was carried out in the high-temperature furnace module of ORNL's severe accident test station (SATS). This system, as depicted in Fig. 1(a), has been described in detail previously [10]; however, a fundamental modification to the system was carried out for the tests in this study where all the alumina furnace components have been replaced with zirconia. The zirconia tubes were manufactured by CoorsTek (Golden, CO) with the manufacture specified composition of $\mathrm{ZrO}_{2}+\mathrm{HfO}_{2}-9 \mathrm{wt} \% \mathrm{Y}_{2} \mathrm{O}_{3}-1$ $\mathrm{wt} \% \mathrm{CaO}-1 \mathrm{wt} \% \mathrm{SiO}_{2}-1 \mathrm{wt} \% \mathrm{Al}_{2} \mathrm{O}_{3}$. This modification was carried out since the previous steam oxidation tests [10] in alumina furnace components resulted in alumina volatilization at temperatures above $1500^{\circ} \mathrm{C}$ (as a result of steam-alumina reaction [18]). Tests carried out in dry oxygen inside alumina tubes have also shown to be affected by the other impurities in these tubes [19]. The volatized alumina was subsequently incorporated into the oxide scale forming on the $\mathrm{SiC}$ materials, changing the chemistry of this layer. By transitioning to zirconia furnace components, this issue was largely mitigated.

The testing on TRISO fuel particles ( $>500$ particles during each run) was carried out while they were held inside a perforated CVD-SiC tray (Dow Chemical Co., Marlborough, MA with a purity > 99.999\%) as shown in Fig. 1(b). Since the outermost layer of the particles consisted of the CVD-SiC coating layer, the particles were only adjacent to each other and the SiC tray; hence no possibility from direct interaction with foreign materials was possible during the tests. Particles without $\mathrm{OPyC}$ were intentionally used since it is known that graphite reacts rapidly in presence of water vapor [11] and also to isolate the study to that of $\mathrm{SiC}$ coating layer oxidation.

Steam oxidation tests were conducted under isothermal conditions and during the temperature ramp up and down the specimens were exposed to flowing ultra-high-purity argon. The steam flow velocity in the system was adjusted by the rate of water injection into the boiler. The gas flow velocity was calculated in a simplistic manner using this injection rate, temperature, and the cross-sectional area of the zirconia furnace tube. The exact steam flow velocity past the particles inside the perforated SiC tray is unknown and can vary depending on the location of the particle in the packed bed. 
After the oxidation tests, the specimens were cross-sectioned for metallographic examination. The particles were polished to mid-plane to attain a perpendicular view of the oxide-carbide interface. The extent of $\mathrm{SiC}$ layer recession was analyzed using a well-developed procedure involving optical microscopy and computer image analysis [20]. Scanning electron microscopy (SEM) studies were conducted with a JEOL 6500 FEG-type microscope operating at $15 \mathrm{kV}$ accelerating potential. X-ray diffraction (XRD) studies were performed using a Rigaku MiniFlex II XRD instrument of $0.45 \mathrm{~kW}$ (30 $\mathrm{kV}$ and $15 \mathrm{~mA}$ ) with $\mathrm{Cu}-\mathrm{K} \alpha$ radiation. For the purposes of the XRD study, the oxidized particles were crushed to remove the zirconia kernels. Subsequently, the coating layers (PyC and $\mathrm{SiC}$ ) along with the surface oxide were ground in a mortar and pestle with ethanol addition into a fine powder slurry. The slurry was then spread onto a low-background holder for the diffraction experiment. A small amount of Si standard (SRM640b) was added to the spread slurry to be utilized during Rietveld refinement as a reference.

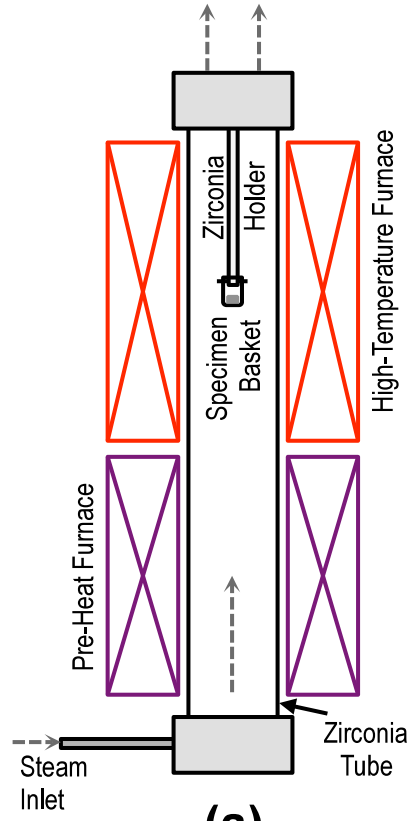

(a)

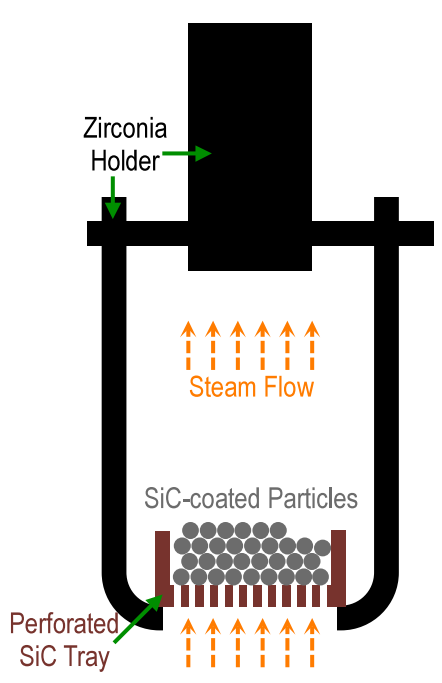

(b)

Figure 1. a) Depiction of the high-temperature furnace with zirconia furnace components and b) the state of SiCcoated particles inside the specimen basket during oxidation tests.

\section{Results}

\subsection{Optical microscopy and image analysis}

The summary of oxidation test conditions and results on SiC-coated particles is provided in Table 1. The $\mathrm{SiC}$ layer thickness prior to and after various oxidation tests was determined via optical microscopy and computer image analysis from roughly 50 particles, an example of which is shown in Fig. 2(a). Fig. 2(b) shows the processed image of the same particle in Fig. 2(a), where the software determined the thickness of coating layers by quantifying the distance of the various interfaces from the center of the particle, as 
described in ref [20]. The oxide layer thickness reported in Table 1 was determined from SEM results in Fig. 3, as described in the next subsection.

Table I. Summary of SiC-coated particle oxidation tests. All tests are in $100 \% \mathrm{H}_{2} \mathrm{O}$ except test \#5 that was conducted in flowing air.

\begin{tabular}{ccccccc}
\hline ID & $\begin{array}{c}\text { Test Temperature } \\
{\left[{ }^{\circ} \mathrm{C}\right]}\end{array}$ & $\begin{array}{c}\text { Test Duration } \\
{[\mathrm{h}]}\end{array}$ & $\begin{array}{c}\text { Gas Flow } \\
\text { Velocity }[\mathrm{cm} / \mathrm{s}]\end{array}$ & $\begin{array}{c}\text { Mean SiC Layer } \\
\text { Thickness }[\mu \mathrm{m}]\end{array}$ & $\begin{array}{c}\text { SiC Layer Thickness } \\
\text { Std. Dev. }[\mu \mathrm{m}]\end{array}$ & $\begin{array}{c}\text { Oxide Layer } \\
\text { Thickness }[\mu \mathrm{m}]\end{array}$ \\
\hline 1 & & As fabricated & & 32.2 & 0.7 & 0 \\
2 & 1500 & 4 & 57 & 30.2 & 0.9 & 2.3 \\
3 & 1600 & 4 & 60 & 30.1 & 0.9 & 3.1 \\
4 & 1600 & 24 & 60 & 29.7 & 1.0 & 6.9 \\
$5^{*}$ & 1600 & 24 & $13^{*}$ & 33.6 & 1.5 & 3.1 \\
6 & 1550 & 24 & 58 & 32.4 & 1.1 & 4.4 \\
7 & 1650 & 24 & 62 & 31.9 & 0.9 & 3.7 \\
8 & 1700 & 4 & 63 & 30.8 & 1.0 & 7.2 \\
\hline
\end{tabular}

${ }^{*}$ Test performed in flowing air.
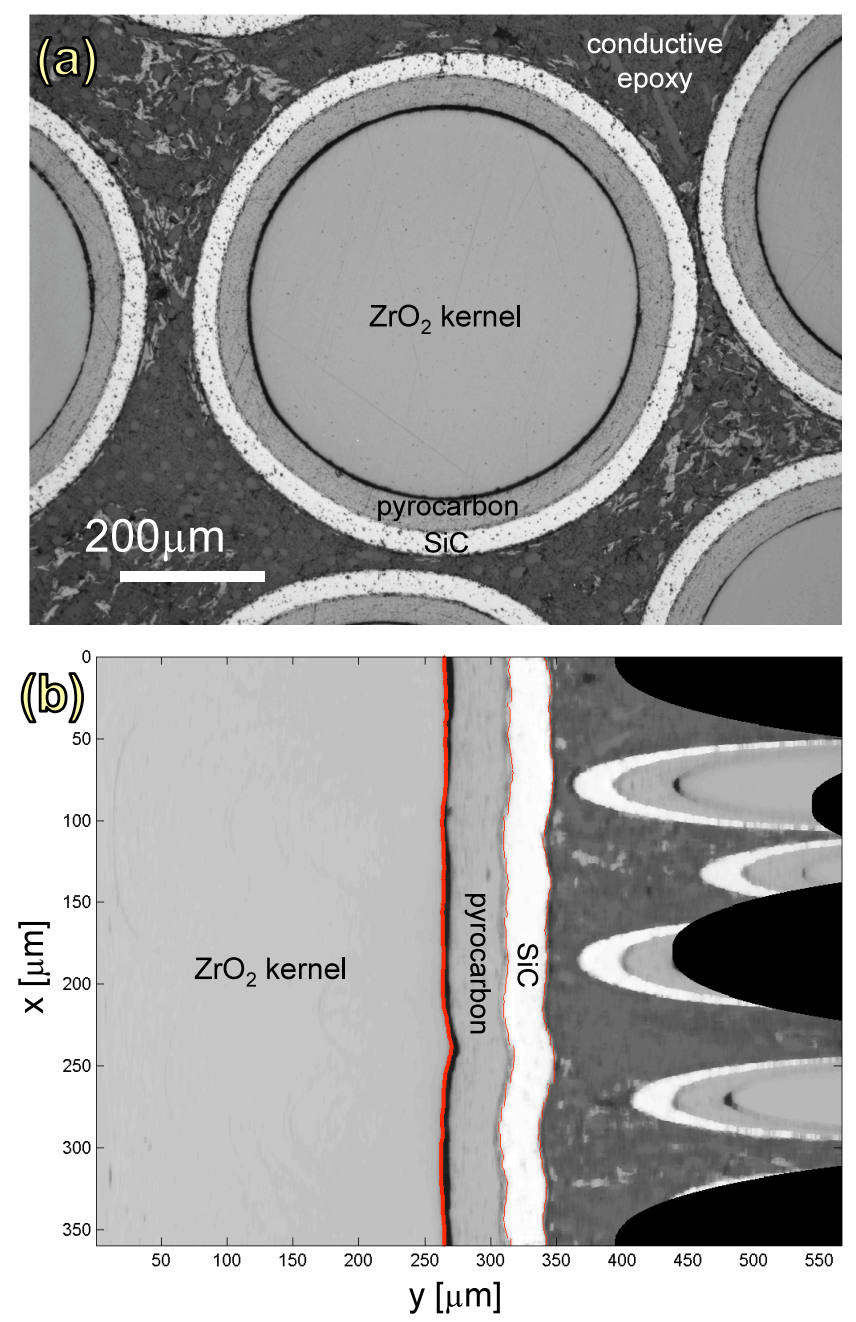
Figure 2. a) Optical image of the SiC-coated particle after oxidation and polished to the mid-plane and b) computer image analysis of the same particle for determining SiC layer thickness. Essentially, $\mathrm{y}=0$ is the center of the particle and the distance form this origin are measured for various layers. The red lines indicate the computer recognized location of the interfaces.

As it is suggested by Table 1, the extent of $\mathrm{SiC}$ coating layer recession proved negligible after the various oxidation tests. The starting $\mathrm{SiC}$ coating layer thickness varies among the particles after the deposition step; as noted by the standard deviation of $0.7 \mu \mathrm{m}$ in the SiC layer thickness in the as-fabricated state. Note that the magnitude of $\mathrm{SiC}$ layer thickness change is within a few standard deviations of the mean value of the as-fabricated batch. Figure 4(a) shows the distribution in all the thickness measurements using boxplots. Given the small amount of $\mathrm{SiC}$ layer thickness recession and the large statistical distribution of the results, no detailed kinetic data could be extracted. However, as shown in Figure 4(b), the average magnitudes of thickness change and the trends (essentially thickness loss in steam and gain in air) are consistent with prior data from $\mathrm{SiC}$ oxidation tests in air and steam [10, 21-22]. As expected, Fig. 4(b) also shows that $\mathrm{SiC}$ recession increases with time in the flowing steam environment.

\subsection{Scanning electron microscopy}

The oxide layer thickness was determined from the backscattered SEM images, as shown in Fig. 3. It is possible to predict the oxide layer thickness given the well-developed paralinear oxidation kinetics of $\mathrm{SiC}$ in the presence of water vapor [23]. The kinetic data and model of Terrani et. al. [10] have been used for this prediction and compared to the current results. This comparison was performed in Fig. 5 where the data is in sufficient agreement ( $\pm 50 \%$ of the prediction). Note that the kinetic data from ref. [10] were determined from tests in an alumina furnace and are only applicable up to $1600^{\circ} \mathrm{C}$ and the results beyond this point in Fig. 5 have been extrapolated. In particular, prior tests at $1700^{\circ} \mathrm{C}$ inside the alumina furnace resulted in melting of the silica layer [10], however, by transition to the zirconia furnace tube, the oxide layer remained solid. The presence of bubbles at the oxide carbide interface, likely filled with the $\mathrm{H}_{2}$ and $\mathrm{CO}$ reaction byproducts as a result of steam oxidation of $\mathrm{SiC}$, were noted after $1700^{\circ} \mathrm{C}$ exposure.

Surface characteristics of the oxide layers were also documented and are shown in Fig. 6. These results are comparable to what was reported for bulk CVD-SiC [10], excluding the current observation at $1700^{\circ} \mathrm{C}$ where no sign of oxide layer liquefaction was noted after tests inside the zirconia furnace tube. Crystalline surface oxides undergo cracking upon cooling due to the strong mismatch in CTE with the substrate $\mathrm{SiC}$ as discussed in ref [10], and also due to the $\alpha \rightarrow \beta$ phase transformation in cristobalite at low temperatures $\left(\sim 270^{\circ} \mathrm{C}\right)$ [24]. Note that the surface features of the silica layer after air exposure at $1600^{\circ} \mathrm{C}$ appear similar to the original surface topography of the as fabricated $\mathrm{SiC}$ shell. This is indicative of the absence of any volatilization in this dry air environment. Also in Fig. 6(b), the thin oxide layer, as seen in Fig. 3 (b), resembles the as-fabricated surface and is not smooth. This is likely due to the slow rate of $\mathrm{SiO}_{2}$ volatilization from the surface.

Energy dispersive $\mathrm{x}$-ray spectroscopy (EDS) was used to characterize the silica layers and to detect presence of any appreciable amount of impurities after $1500-1700^{\circ} \mathrm{C}$ exposures, Fig. 7. No sign of $\mathrm{Zr}$ incorporation into the oxide layer was observed. However, a small Al impurity may be present in the oxides, the source of which may be the residual amounts of alumina in the zirconia furnace tube. 


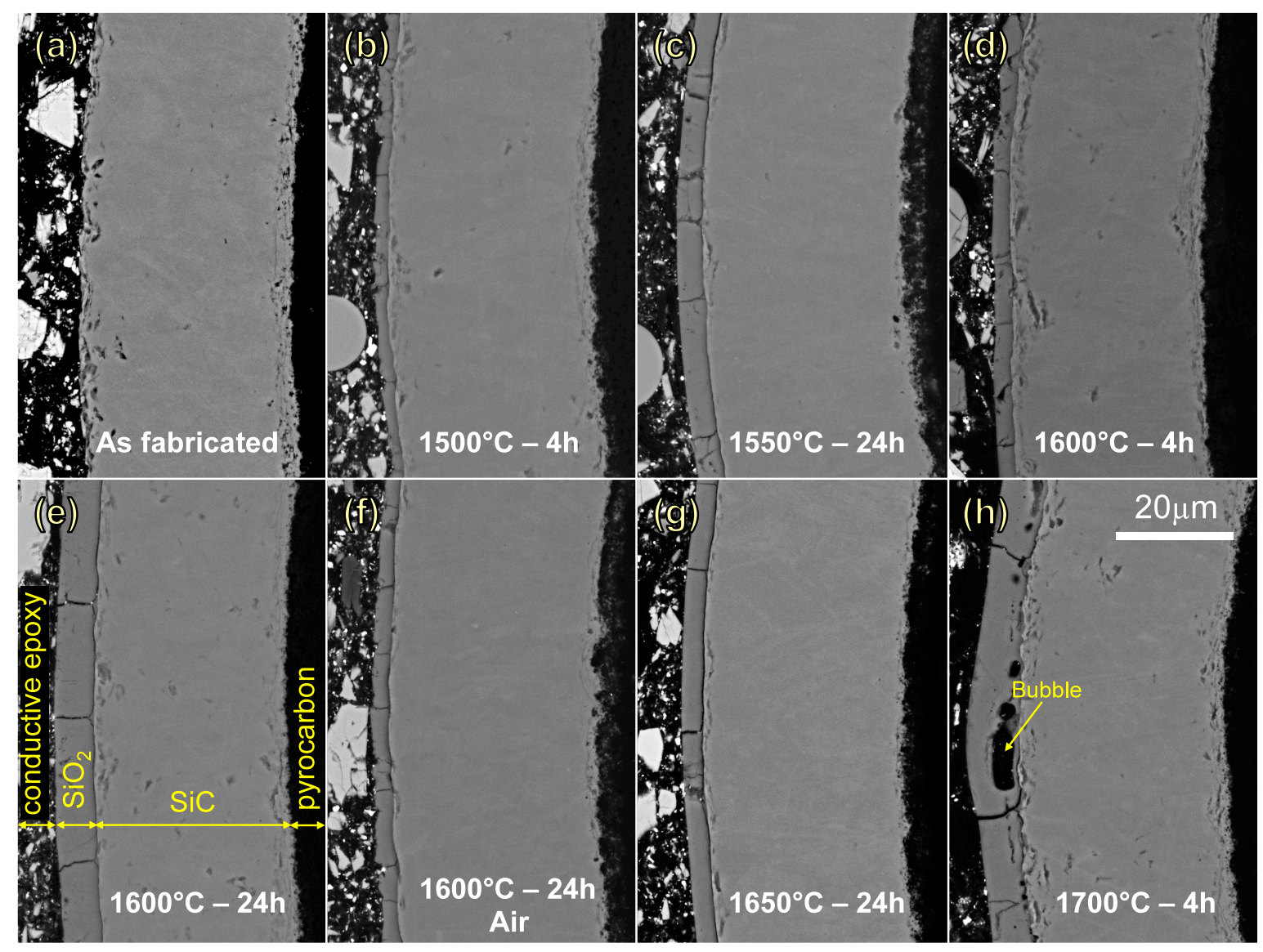

Figure 3. Backscattered electron image of $\mathrm{SiC}$ coating layer cross-section prior and after oxidation. 

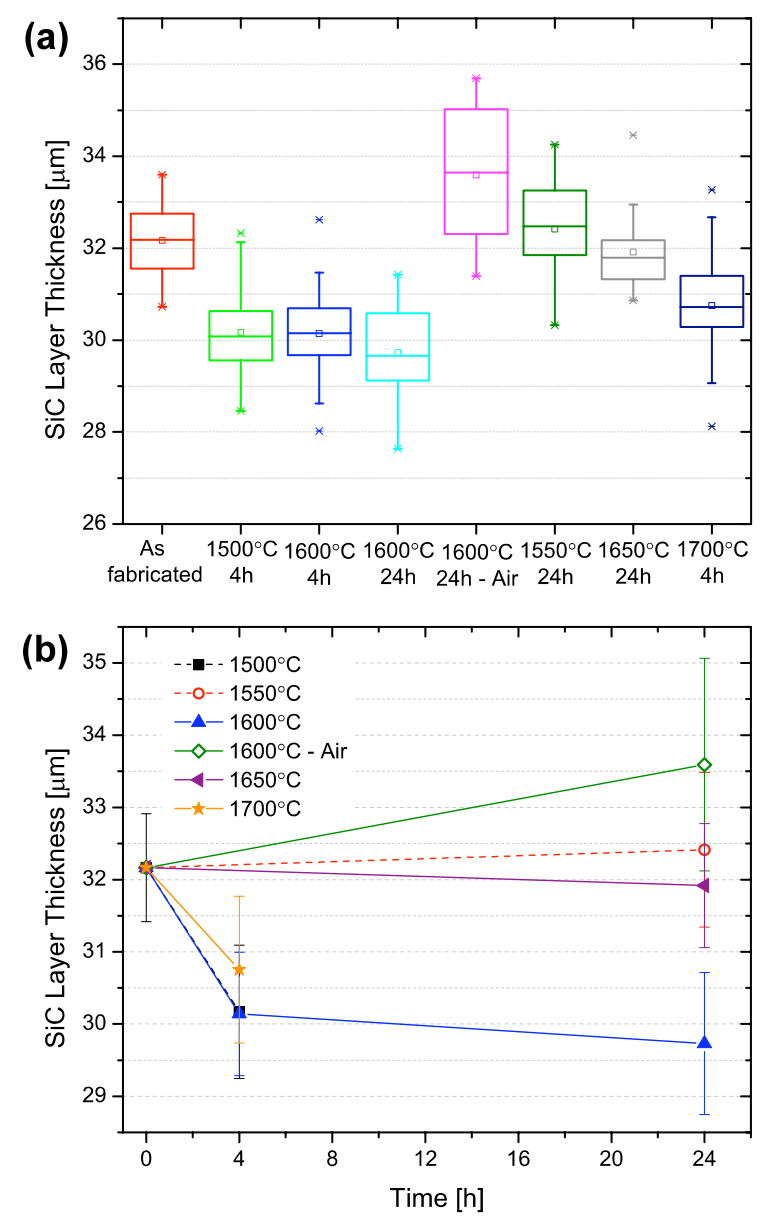

Figure 4. a) Boxplot representation of the $\mathrm{SiC}$ coating layer thickness distribution and b) variation of mean $\mathrm{SiC}$ layer thickness with time under high-temperature steam or air environments (error bars are std. dev.).

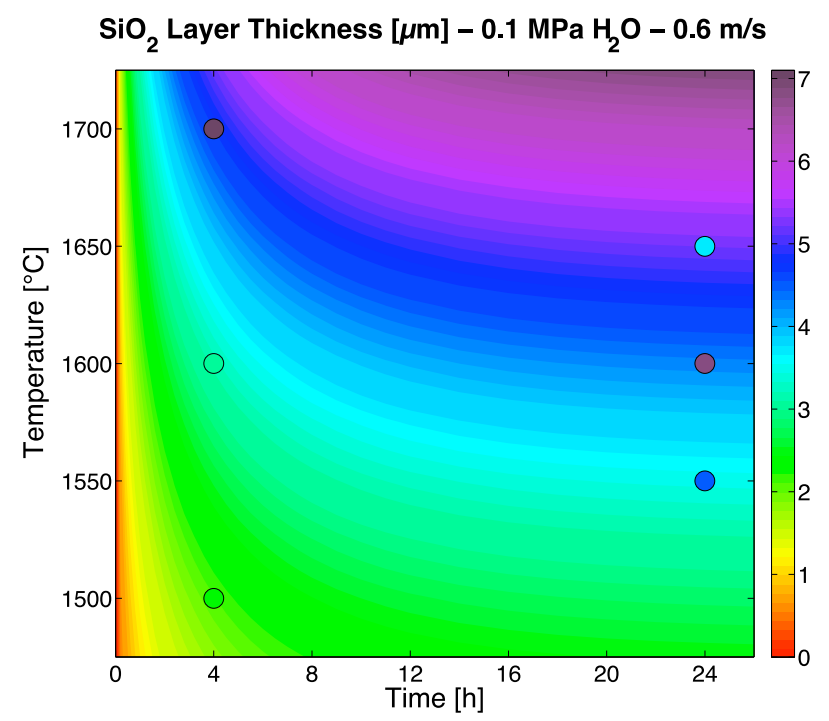


Figure 5. Comparison between kinetic data prediction of $\mathrm{SiO}_{2}$ layer thickness from correlations in ref. [10] (contour map) and measured thickness of $\mathrm{SiO}_{2}$ layer from SEM images in Fig 3 (scatter circles). The prediction assumes steam pressure at $1 \mathrm{~atm}$ and steam flow rate at $0.6 \mathrm{~m} / \mathrm{s}$.

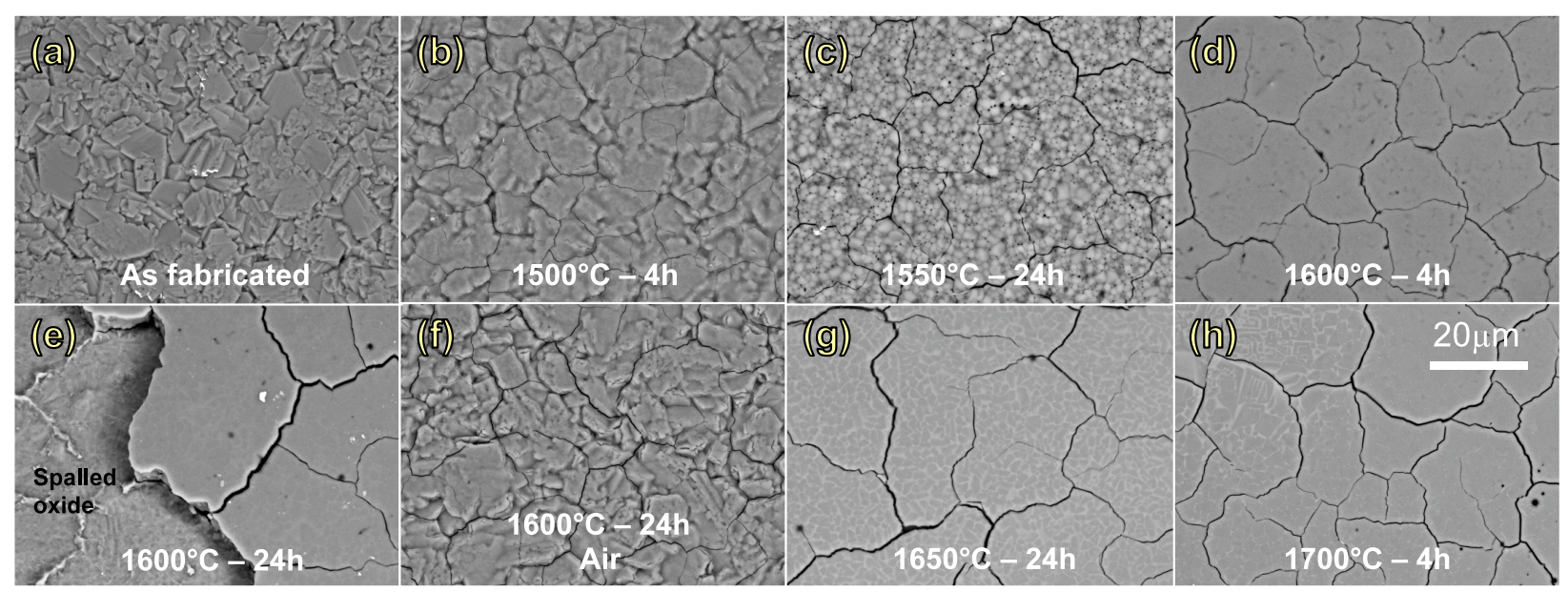

Figure 6. Backscattered electron image of as-fabricated $\mathrm{SiC}$ coating layer surface and the resulting silica layer surface after various oxidation tests in flowing steam, except for (f) that was carried out in dry air.

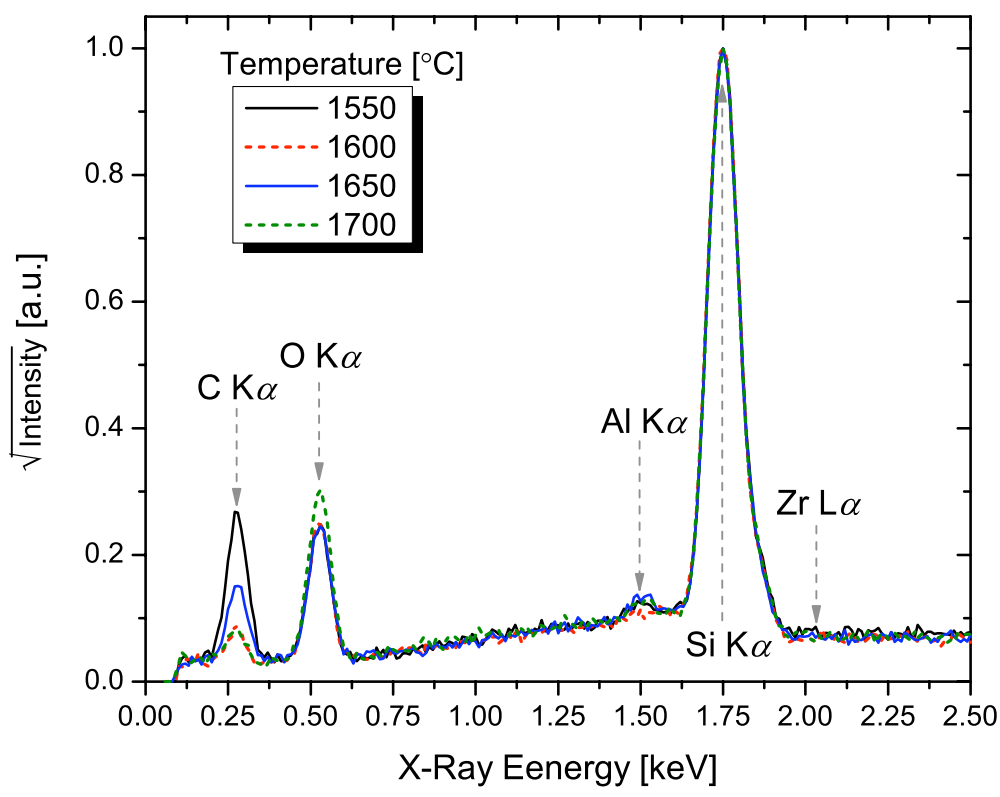

Figure 7. Characteristic x-ray spectra from oxides formed on the surface of $\mathrm{SiC}$ coating layer after $24 \mathrm{~h}$ steam exposure between $1550-1700^{\circ} \mathrm{C}$. The square root of normalized intensity is plotted to exaggerate minor peaks.

\subsection{X-ray diffractometry}

Fig. 8 shows a selected portion of the XRD patterns collected from $10-120^{\circ} 2 \theta$ from the coating layers of the particles exposed to air and steam for $24 \mathrm{~h}$ at $1600^{\circ} \mathrm{C}$ and for $4 \mathrm{~h}$ to $1700^{\circ} \mathrm{C}$ steam. The patterns are 
complex since the Si standard, multiple phases of silica, $\mathrm{SiC}$, and graphite are all present in these samples. Rietveld refinement on the spectra was performed with the General Structure Analysis System (GSAS) software package [25] over the entire collected spectrum. The important observation here is that under all these oxidation conditions, two polymorphs of silica were detected; the dominant polymorph was $\alpha$ cristobalite ( $P 4_{1} 2_{1} 2$ space group) that forms upon cooling from its high-temperature counterpart, $\beta$ cristobalite. Also, minor amounts of $\alpha$-quartz $\left(P 3_{1} 21\right.$ space group) were also detected, likely present after cooling from $\beta$-quartz. In our previous steam oxidation study on bulk CVD specimens inside an alumina tube furnace [10], only formation of $\alpha$-cristobalite was detected after $1400-1600^{\circ} \mathrm{C}$ exposures. No $\alpha-$ tridymite was detected to be present in these samples.

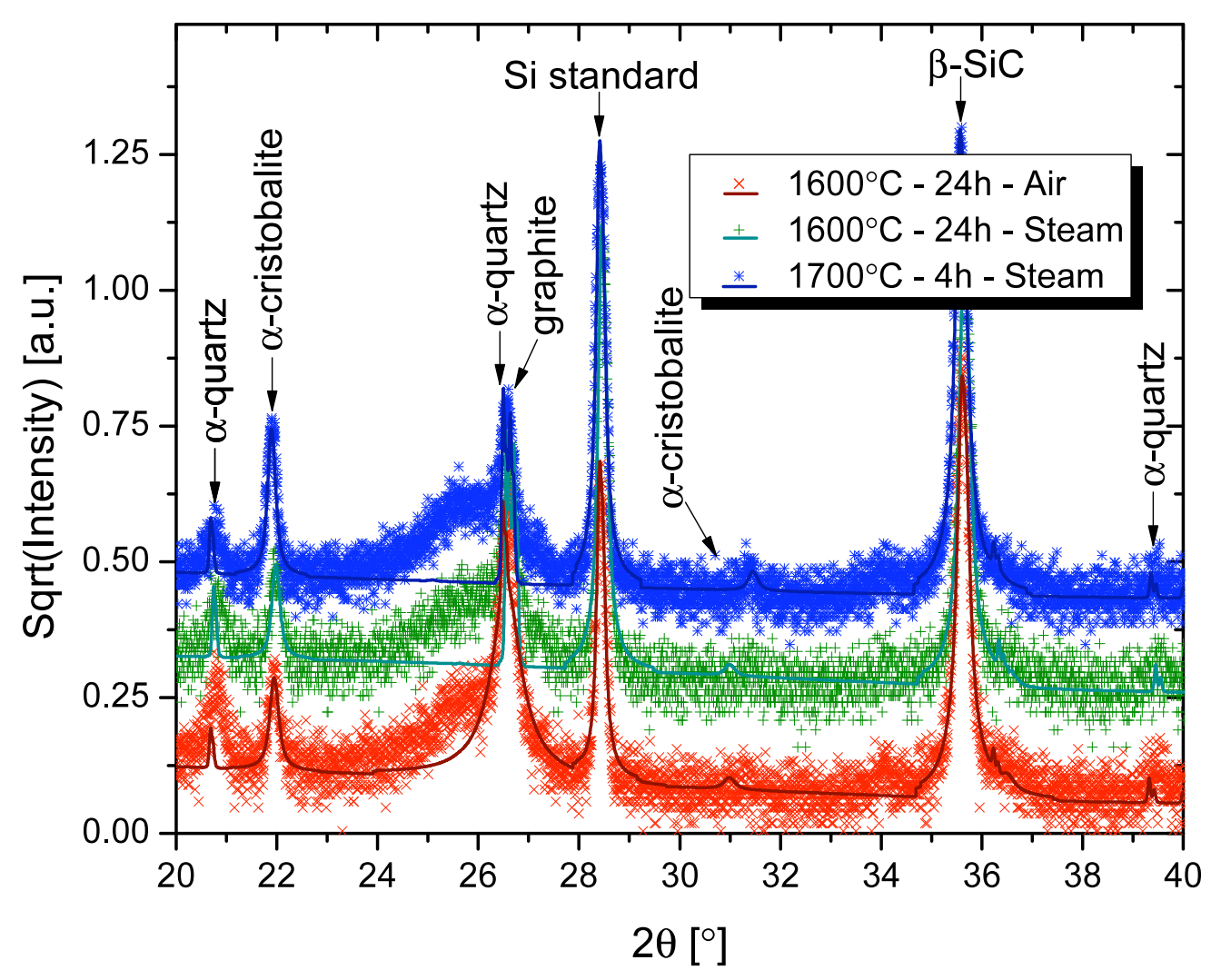

Figure 8. X-ray diffraction patterns along with the Rietveld refinement fit (solid lines) from oxidized SiC coating layer after $24 \mathrm{~h}$ air and steam exposures at $1600^{\circ} \mathrm{C}$ and $4 \mathrm{~h}$ steam exposure at $1700^{\circ} \mathrm{C}$. The square root of normalized intensity is plotted to exaggerate minor peaks. The different spectra are arbitrarily shifted upward for clarity.

\section{Summary}


Oxidation of $\mathrm{SiC}$ coating layer of TRISO fuel particles in high-temperature $\left(1500-1700^{\circ} \mathrm{C}\right)$ flowing steam environments was examined for up to $24 \mathrm{~h}$. The CVD-SiC coating layer exhibits very good steam oxidation resistance where no thickness loss beyond $2.5 \mu \mathrm{m}$ was observed up to $24 \mathrm{~h}$ under these conditions. The thickness of the oxide layer present on the surface of the $\mathrm{SiC}$ coating layer under these conditions was consistent with prior steam oxidation tests on bulk high-purity CVD-SiC, indicating similar behavior between these coating layers and the bulk material. Instead of an alumina furnace tube, the zirconia furnace tube that was used in this study largely eliminated deposition of $\mathrm{Al}$ impurities into the silica layer during the steam exposure tests. The absence of $\mathrm{Al}$ impurities appears to have in turn eliminated melting of the silica at $1700^{\circ} \mathrm{C}$. Consistent with prior literature, the major crystalline polymorph of silica present on the surface of $\mathrm{SiC}$ coating layers after these exposures was cristobalite. However, a notable extent of quartz was also found to be present.

These results indicate that under postulated severe accident conditions (for a HTGR or a LWR) where water vapor is present at temperatures up to $1700^{\circ} \mathrm{C}$, the $\mathrm{SiC}$ coating layer of TRISO fuel particles will be effective in retaining fission products up to many hours. The reader should note that this conclusion is derived based on tests on a limited number of particles. Therefore, the statistical nature of defects (e.g. cracks) that could exist in the $\mathrm{SiC}$ coating layers may result in release of a small fraction of fission product inventory from susceptible particles.

\section{Acknowledgments}

The aid and technical insight of Mike Howell, Ivan Dunbar, John Hunn, Bruce Pint and Lance Snead at ORNL is gratefully acknowledged. Sebastien Dryepondt provided useful comments on the manuscript. The work

presented in this paper was supported by the Advanced Fuels Campaign of the Fuel Cycle R\&D program in the Office of Nuclear Energy, US Department of Energy.

\section{References}

[1] H. Nickel; H. Nabielek; G. Pott; A. Mehner, Nuclear Engineering and Design 2002, 217 (1), 141-151.

[2] D. Petti; J. Maki; J. Hunn; P. Pappano; C. Barnes; J. Saurwein, et al., JOM Journal of the Minerals, Metals and Materials Society 2010, 62 (9), 62-66.

[3] L. L. Snead; T. Nozawa; Y. Katoh; T. S. Byun; S. Kondo; D. A. Petti, Journal of Nuclear Materials 2007, 371 (1-3), 329-377.

[4] S. J. Zinkle; K. A. Terrani; J. C. Gehin; L. J. Ott; L. L. Snead, Journal of Nuclear Materials 2014, 448, 374-379.

[5] D. M. Carpenter. An assessment of silicon carbide as a cladding material for light water reactors. Massachusetts Institute of Technology, 2010.

[6] K. Yueh; K. A. Terrani, Journal of Nuclear Materials 2014, 448, 380-388.

[7] E. J. Opila, Journal of the American Ceramic Society 1999, 82 (3), 625-636.

[8] E. J. Opila, Journal of the American Ceramic Society 2003, 86 (8), 1238-1248.

[9] Y. Lee; T. J. McKrell; C. Yue; M. S. Kazimi, Nuclear Technology 2013, 183 (2), 210-227.

[10] K. A. Terrani; B. A. Pint; C. M. Parish; C. M. Silva; L. L. Snead; Y. katoh, Journal of American Ceramic Society 2014, 97 (8), 2331-2352.

[11] C. I. Contescu; R. W. Mee; P. Wang; A. V. Romanova; T. D. Burchell, Journal of Nuclear Materials 2014, $453,225-232$.

[12] In Full issue, Response of fuel, fuel elements, and gas cooled reactor cores under accidental air or water ingress conditions, IAEA TECDOC-784, Beijing, China, 25-27 October; Beijing, China, 1993.

[13] K. A. Terrani; L. L. Snead; J. C. Gehin, Journal of Nuclear Materials 2012, 427 (1-3), 209-224. 
[14] K. A. Terrani; J. O. Kiggans; Y. Katoh; K. Shimoda; F. C. Montgomery; B. L. Armstrong, et al., Journal of Nuclear Materials 2012, 426 (1-3), 268-276.

[15] S. Singhal; F. Lange, Journal of the American Ceramic Society 1975, 58 (9-10), 433-435.

[16] S. C. Singhal, Journal of Materials Science 1976, 11 (7), 1246-1253.

[17] J. Costello; R. Tressler, Journal of the American Ceramic Society 1981, 64 (6), 327-331.

[18] E. J. Opila; D. L. Myers, Journal of the American Ceramic Society 2004, 87 (9), 1701-1705.

[19] E. Opila, Journal of the American Ceramic Society 1995, 78 (4), 1107-1110.

[20] A. K. Kercher; J. D. Hunn; J. R. Price; P. Pappano, Journal of Nuclear Materials 2008, 380 (1), $76-84$.

[21] L. U. Ogbuji; E. J. Opila, Journal of the Electrochemical Society 1995, 142 (3), 925-930.

[22] D. S. Fox, Journal of the American Ceramic Society 1998, 81 (4), 945-950.

[23] E. J. Opila; R. E. Hann, Journal of the American Ceramic Society 1997, 80 (1), 197-205.

[24] D. M. Hatch; S. Ghose, Physics and Chemistry of Minerals 1991, 17 (6), 554-562.

[25] A. C. Larson; R. B. Von Dreele, General Structure Analysis System. LANSCE, MS-H805, Los Alamos, New Mexico 1994. 